\title{
Ser mãe e portadora do HIV: dualidade que permeia o risco da transmissão vertical
}

\section{Being a mother and HIV positive: a duality permeating the risk of vertical transmission Ser madre y VIH-positiva: dualidad que permea el riesgo de transmisión vertical}

\author{
Carolina Lélis Venâncio Contim'; Elis Oliveira Arantes"II ;êda Maria Ávila Vargas Dias ${ }^{\text {III; }}$ \\ Lílian do Nascimento ${ }^{I V}$; Luisa Pereira Siqueira ${ }^{V}$; Thalita Lima Dutra ${ }^{V I}$
}

\begin{abstract}
RESUMO: A Síndrome da Imunodeficiência Adquirida (AIDS), considerada uma pandemia mundial, atinge mulheres e crianças devido ao risco de transmissão vertical na gestação. Logo, objetivou-se discutir a vivência da mulher na dualidade de ser mãe e conviver com o Vírus da Imunodeficiência Humana (HIV). A abordagem foi quantiqualitativa, utilizando-se de uma entrevista semiestruturada com 35 mães em um serviço de assistência especializada de uma cidade da Zona da Mata Mineira, entre setembro/2009 e março/2010, seguida da análise de conteúdo. Dos resultados emergiram quatro categorias temáticas: Descobrindo ser mãe e portadora do HIV; O temor da transmissão vertical e do preconceito; Amamentar: sonho ou realidade; Enfrentando as implicações decorrentes do reverso da amamentação. Conclui-se que a dualidade de estar grávida e ser portadora do HIV demanda uma assistência qualificada em que o papel do enfermeiro é essencial na condução desse processo. Palavras-Chave: Enfermagem; HIV; gestação; amamentação.
\end{abstract}

\begin{abstract}
Considered a global pandemic, Acquired Immune Deficiency Syndrome affects women and children due to the risk of vertical transmission during pregnancy. Accordingly, this study discussed women's experience of the duality of being a mother and a carrier of the Human Immunodeficiency Virus (HIV). The approach was quanti-qualitative, using semi-structured interviews of 35 mothers at a specialized support service in a town of the Zona da Mata, Minas Gerais, between September 2009 and March 2010. Content analysis of the transcripts revealed four themes: discovering oneself to be a mother and HIVpositive; fear of vertical transmission and prejudice; breastfeeding: dream or reality? and facing the implications of reverso da amamentação\#? rapid weaning\#early cessation. It follows that the duality of being pregnant and HIV positive calls for skilled care in which the nurse's role is essential in conducting this process.
\end{abstract}

Keywords: Nursing; HIV; pregnancy; breast feeding.

RESUMEN: El Síndrome de Inmunodeficiencia Adquirida (SIDA), considerado una pandemia mundial, llega a las mujeres y los niños debido al riesgo de la transmisión vertical durante el embarazo. Por lo tanto, este estudio tuvo como objetivo presentar la experiencia de las mujeres en la dualidad de ser una madre y convivir con el Virus de la Inmunodeficiencia Humana (VIH). El enfoque, cuantitativo/cualitativo, ha utilizado una entrevista semiestructurada con 35 madres de un servicio de asistencia especializada de una ciudad de Zona da Mata de Minas Gerais entre septiembre/2009 y marzo/2010, seguido de un análisis de contenido. Los resultados destacan cuatro categorías temáticas: Descubriendo ser madre y VIH-positiva; El temor a la transmisión vertical y al prejuicio; Lactancia: sueño o realidad; Enfrentando las implicaciones en consecuencia del impedimento de la lactancia materna. Se concluye que la dualidad de estar embarazada y se VIH-positiva exigen una asistencia cualificada en la que el rol del enfermero es esencial para la realización de este proceso.

Palabras Clave: Enfermería; VIH; embarazo; lactancia materna.

\section{INTRODUÇÃO}

De acordo com relatório publicado pelo Programa Conjunto das Nações Unidas sobre HIV/ AIDS, o número de crianças nascidas com o Vírus da Imunodeficiência Humana (HIV) teve um decréscimo de 78\% entre 2001 e $2013^{1}$. Estar grávida e descobrir-se portadora do HIV leva algumas mulheres a adotarem ações preventivas da transmissão vertical. Um exemplo dessas ações é a recomendação de que mães com diagnóstico de soropositividade para o HIV não amamentem seus filhos. Embora muito eficaz, tal medida leva as puérperas a sentimentos de dor e conflitos como medo, tristeza, angústia e culpa, pois, além

\footnotetext{
IAcadêmica da Faculdade de Enfermagem da Universidade Federal de Juiz de Fora. Minas Gerais, Brasil. E-mail: carolvenancioad@hotmail.com. IIAcadêmica da Faculdade de Enfermagem da Universidade Federal de Juiz de Fora. Minas Gerais, Brasil. E-mail: elisarantes@yahoo.com.br. IIIDocente, Doutora do Departamento Materno Infantil da Faculdade de Enfermagem da Universidade Federal de Juiz de Fora. Minas Gerais, Brasil. E-mail: vargasdias@hotmail.com.

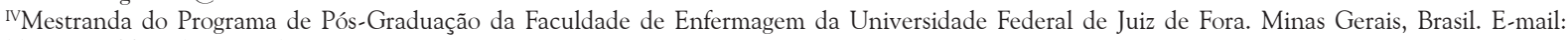
lilianurseufff@yahoo.com.br.

vAcadêmica da Faculdade de Enfermagem da Universidade Federal de Juiz de Fora. Minas Gerais, Brasil. E-mail: luisasiqueira@uai.com.br.

${ }^{\mathrm{VI}}$ Acadêmica da Faculdade de Enfermagem da Universidade Federal de Juiz de Fora. Minas Gerais, Brasil. E-mail: thatadutra@hotmail.com.
} 
de serem portadoras e transmissoras do vírus, ainda se deparam com a impossibilidade de aleitamento, sentindo-se reduzidas quanto ao seu papel de mulher e mãe na sociedade 2 .

Considerando que a possibilidade da transmissão vertical do HIV pode causar disfunção em processos biológicos, emocionais, psicológicos e sociais nas mães que contraíram este vírus - chegando, muitas vezes, a interferir na criação do vínculo afetivo com o filho -, delimitou-se a maternidade com o diagnóstico positivo para o HIV como objeto de estudo da presente investigação.

A relevância do estudo reside no fato de que, para a efetivação de um cuidado integral, é necessário que a enfermagem entenda e conheça o contexto social, cultural e psicológico no qual se encontram essas mulheres. Isto deverá fazer parte das prioridades do plano assistencial, pois compõe o que é chamado de assistência qualificada, o que, certamente, faz a diferença na vida das clientes ${ }^{3}$. O tratamento igualitário, livre de rótulos e discriminação também é traduzido no acolhimento dessa mulher ${ }^{4}$. Ademais, objetivou-se discutir a vivência da mulher na dualidade de ser mãe e portadora do HIV.

\section{ReVISÃo DE LITERATURA}

A Síndrome da Imunodeficiência Adquirida (AIDS) pode ser concebida como uma pandemia que impõe implicações na prevenção, assistência e processo educativo de seus acometidos. Direciona, nos últimos anos, a atenção da comunidade científica na identificação dos indivíduos envolvidos diretamente com a doença ${ }^{5}$. Em consonância a esses fatos, dados publicados, em 2014, pela Organização das Nações Unidas (ONU), apontam para um recuo de $27 \%$ no número de infectados pelo HIV no mundo, mas, em contrapartida, um aumento de $11 \%$ no Brasil, entre os anos de 2005 e $2013^{6}$.

No Brasil, a evolução da AIDS afetou de maneira especial as mulheres e originou o fenômeno conhecido como feminização da epidemia, termo usado para demonstrar a vulnerabilidade feminina à exposição ao vírus ${ }^{3}$. Ao serem inseridas no âmbito da AIDS, muitas mulheres foram infectadas em idade fértil e, consequentemente, as crianças foram constituindo um grupo também crescente para a infecção pelo HIV, por meio da transmissão vertical ${ }^{7}$.

De acordo com Ministério da Saúde, denominase transmissão vertical do HIV a situação em que a criança é infectada pelo vírus durante a gestação, parto ou amamentação pela mãe ou por outra mulher com sorologia positiva para o $\mathrm{HIV}^{8}$.

Compreende-se que sorologias para sífilis e HIV são exigências essenciais durante a assistência ao pré-natal, conforme orientação do Ministério da Saúde ${ }^{9}$. Atualmente, uma parcela considerável dos diagnósticos de casos de infecção retroviral na população feminina ocorre durante o período gestacional, mediante a triagem sorológica anti-HIV, refletindo a adequação da política de saúde na atenção pré-natal, mas, ao mesmo tempo, contrasta com as medidas de prevenção das doenças sexualmente transmissíveis (DST), dentre elas o HIV ${ }^{10}$.

Isso porque se verifica um aumento no número de notificações de mulheres heterossexuais infectadas pelo vírus HIV. Esse cenário tem ocorrido de modo substancial em cidades de pequeno a médio porte no interior do país. São mulheres em idade reprodutiva, com baixos níveis de renda e escolaridade, que, ao contrair o vírus, podem promover um aumento de casos de crianças infectadas, por intermédio da transmissão vertical ${ }^{11}$.

\section{Metodologia}

Trata-se de um estudo de abordagem quantiqualitativa, que teve como cenário um serviço de assistência especializada (SAE) de uma cidade da Zona da Mata Mineira, local em que é desenvolvido o Programa de DST/AIDS.

Após autorização do serviço e aprovação do Comitê de Ética em Pesquisa da Universidade Federal de Juiz de Fora, parecer no 092/2009, foi iniciada a fase de coleta de dados, por meio de uma entrevista semiestruturada, em que foram abordadas questões fechadas e abertas sobre o perfil sociodemográfico e dados relativos ao objeto de estudo.

Os sujeitos foram mães com sorologia positiva para o HIV, usuárias do referido serviço, maiores de 18 anos, que aceitaram, de forma voluntária, participar do estudo, assinando o Termo de Consentimento Livre e Esclarecido. O critério de inclusão na pesquisa consistiu no perfil de mães com filhos em idade igual ou inferior a dois anos (período de acompanhamento da criança no serviço, para confirmação ou não da transmissão vertical).

As mães que autorizaram a gravação da entrevista tiveram suas identidades preservadas, seus nomes foram substituídos pela letra $\mathrm{M}$, seguida de um número de identificação, garantindo, portanto, a legitimidade, a integridade e o anonimato dos sujeitos pesquisados, em respeito aos princípios preconizados pela Resolução n 466/2012 do Conselho Nacional de Saúde.

A coleta de dados foi realizada no período de setembro de 2009 a março de 2010. O número de participantes não foi determinado previamente, sendo definido a partir do ponto de saturação que consiste na repetição das informações repassadas pelas participantes, totalizando 35 mães.

Ao término da coleta e transcrição dos dados, partiu-se para a fase de análise estatística, mensurando-se as frequências absolutas e percentuais do perfil sociodemográfico das participantes. A análise das informações 
presentes nas questões abertas, mediante a descrição das categorias definidas por meio da leitura flutuante do texto, permitiu realizar a seleção de conteúdos. Iniciou-se a fase de exploração do material, sendo os dados organizados e reunidos em unidades de registro pelo recorte e decodificação do conteúdo. Foi utilizada a escolha das unidades de registro e a categorização ${ }^{12}$.

\section{Resultados e Discussão}

As mães possuíam idade entre 18 e 49 anos, renda familiar variando entre menos de um salário mínimo a mais de três salários mínimos; somente $2(5,71 \%)$ possuíam renda familiar superior a três salários, mas que não passava de cinco salários mínimos. Destacam-se 25 (71,4\%) mulheres que viviam com seus companheiros, sendo 19 (54,3\%) em união estável e $6(17,1 \%)$ casadas. Em relação ao número de filhos, 28 (80\%) possuíam mais de um filho vivo.

Quanto à escolaridade, a maior parte das entrevistadas possuía o ensino fundamental incompleto. Uma das participantes, inclusive, não era alfabetizada, o que permite constatar um baixo nível de instrução educacional, dificultando ao indivíduo obter conhecimento e informações sobre sua saúde e como cuidar dela.

Dessa forma, a análise das entrevistas permitiu a construção de quatro categorias, analisadas a seguir.

\section{Descobrindo ser mãe e portadora do HIV}

Nesta primeira categoria, foram questionadas sobre como e quando foi a descoberta do diagnóstico de soropositividade para o HIV. A maioria das participantes referiu ter ocorrido durante a realização do pré-natal. Entretanto, em alguns casos, a descoberta também ocorreu a partir do aparecimento de alguns sintomas, da realização do teste rápido, na maternidade, no momento do parto e pela confirmação sorológica do companheiro.

Contraí de um namorado meu que eu nem imaginava; o cara morreu de meningite, aí fui ver que a meningite era por causa do HIV que facilitou a infecção, dai eu fiz o teste, quando vi que ele tinha morrido já sabia que eu estava contaminada. (M3)

A detecção precoce, ainda no pré-natal, é fundamental, pois é possível instituir a quimioprofilaxia a tempo para prevenção da transmissão vertical. Estudos mostram que o uso da Zidovudina (AZT) em mulheres grávidas e com diagnóstico de soropositividade para HIV durante o pré-natal e no momento do parto, e no bebê, durante as seis primeiras semanas de vida, reduz em dois terços a transmissão do vírus para as crianças ${ }^{13}$.

Referindo-se a como foi a descoberta do diagnóstico do HIV, as participantes relataram, unanimemente, ter sido uma situação bastante complicada e sofrida, em que muitos sentimentos foram aflorados, sendo a tristeza o principal deles. Relataram, ainda, que se sentiram perdidas, inconformadas, indignadas e até mesmo decepcionadas com a frieza de alguns profissionais de saúde ao informar o diagnóstico e encaminhá-las aos serviços especializados.

Frente à situação imposta, uma variedade de reações vividas foi mencionada, desde a indiferença até um completo desespero, além do choque, surpresa e revolta. A impotência, diante da nova realidade, também permeou esse momento, que, muitas vezes, culminou na culpa do parceiro pela transmissão do vírus.

Vale destacar que quase a totalidade das participantes referiu ter contraído o HIV de seus parceiros fixos, sendo muitas casadas ou em união estável, o que contradiz o preconceito de que a transmissão do vírus está estritamente relacionada à promiscuidade feminina.

Para as participantes do estudo, o principal agravante do diagnóstico HIV positivo é a dificuldade de revelar para a família. Entretanto, diante do estigma do HIV, a possibilidade de contar com o apoio familiar reduz os obstáculos para assimilar o diagnóstico ${ }^{14}$.

Chama-se a atenção para a importância do profissional de saúde que deve atuar de forma a facilitar a revelação do diagnóstico e o enfrentamento dessa vivência, minimizando os problemas emocionais gerados pelo diagnóstico do HIV positivo, tanto à portadora como aos seus familiares.

\section{O impacto da relação social e o medo da transmissão vertical}

Esta segunda categoria revela que vivenciar a maternidade infectada pelo HIV é uma situação permeada por muitos receios. As participantes relataram ter medo do preconceito da sociedade, principalmente para com os seus filhos; de que seus familiares descubram o seu diagnóstico; de que seus filhos fiquem órfãos; e de que seus filhos se contaminem com o HIV, principalmente pela transmissão vertical.

O meu maior medo é o preconceito, nem é comigo, porque para mim tanto faz, mas é pelos meus filhos, como eles vão ser tratados, se eles serão respeitados, se a sociedade ficar sabendo da minha doença. (M7)

Eu fiquei apavorada, porque eu achei que essa doença mata do dia para a noite e eu nunca mais ia ver meus filhos, meu maior medo era, assim, Deus me levar antes deles. (M9)

O sentimento de culpa por colocar o filho em risco, o medo de infectá-lo e de que ele venha a falecer em consequência da infecção contrastam-se com a concepção idealizada da maternidade, que dá à mulher a capacidade de gerar a vida e assumir um lugar social privilegiado. Nessa situação, evidencia-se o amamentar. A amamentação não é compreendida somente como um ato biológico, abrange, além disso, diversos fatores com diferentes efeitos sobre a dimensão emocional e psicossocial social dos envolvidos ${ }^{15,16}$. 
O preconceito da família e da sociedade em relação ao seu diagnóstico leva muitas mães a não revelarem sua condição de saúde para evitar que ela e seu filho sejam alvos da discriminação social e familiar. Desse modo, acabam delegando o cuidado de seus filhos a pessoas muito próximas, evitando que outros saibam de sua condição sorológica ${ }^{17}$.

Por toda dificuldade vivenciada por essas mães, percebe-se a necessidade de um cuidado de enfermagem humanizado e efetivo voltado para essas mulheres fragilizadas e amedrontadas pelo preconceito e por possível transmissão vertical. Uma estratégia seria a criação de grupos de apoio nos serviços que atendem mães com HIV positivo para que o profissional de saúde possa oferecer uma assistência mais próxima da realidade por elas vivenciada.

Referente à participação em grupos, nenhuma das entrevistadas pertence a grupos de apoio aos portadores do HIV, mas a maioria acredita que seria uma oportunidade de obter mais informações, acolhimento e troca de experiências. As participantes que não demonstraram interesse em participar e justificaram com os mais variados motivos, como: medo de alguém descobrir seu diagnóstico, falta de tempo e poucas condições financeiras para custear o seu transporte até o serviço ou grupo.

[...] vale, é sempre bom aprender, por mais que a gente saiba, entendeu? Porque tem hora que eu fico meio perdida, porque eu não posso contar com ajuda da minha família, entendeu? (M11)

Gostaria de participar, mas não tenho condições; é difícil eu vir aqui para conseguir participar, por condições financeiras, eu moro longe e tenho muito trabalho em casa. (M15)

Por não direcionar ações às mães e crianças, a equipe perde oportunidades valiosas de intervir de modo preventivo e substancial no empoderamento destas mães e, consequentemente, na promoção da saúde de seus conceptos tanto no pré-natal, parto até o pós-parto ${ }^{18}$.

\section{Amamentar: sonho ou realidade}

Constatou-se que a maioria das mães entrevistadas já havia passado pela experiência da amamentação, por terem tido filhos antes da contaminação pelo HIV e/ou por desconhecerem o seu diagnóstico nas gestações anteriores.

As mães que não passaram por essa experiência relatam não terem amamentado seus filhos pelo fato de conhecerem o seu diagnóstico. Todas as entrevistadas mostraram-se cientes do risco da transmissão do vírus pelo leite materno e referiram que por mais doloroso que representasse o reverso da amamentação, esse leite não foi oferecido à criança.

Eu não pude dar de mamar para ela no peito, aí ficou meio estranho, esquisito, mas só de dar na mamadeira a gente sabe, sente, quando se é mãe a gente sente, que ela fica olhando. Quando ela chora, eu faço a mamadeira e dou... e ela fica quietinha. (M13)

[...] a primeira eu amamentei, agora, a segunda eu não pude porque fiquei sabendo do problema. (M16)

Para as mães que já passaram pela experiência da amamentação, o fato de não poder mais oferecer o peito foi difícil, pois temiam perder, em parte, o papel de ser mãe, referindo, inclusive, sentimento de tristeza. Já aquelas que nunca tiveram essa vivência reagiram de maneira menos negativa, sentindo indiferença em relação a esse momento. Para algumas, entretanto, a inexperiência intensificou os sentimentos negativos, pois elas se viram diante da impossibilidade de passar pela amamentação natural, um sonho que habita o universo feminino.

E me senti impotente, não sei explicar direito, eu fiquei muito triste quando soube que não poderia amamentar, mas tem como dar amor de outro jeito, entendeu. Às vezes, eu vejo mães amamentando seus filhos, o neném está no peito e a mãe está olhando para o outro lado, não está nem ligando e isso não quer dizer muita coisa. $\mathrm{O}$ amor que eu sinto não é um leite que vai substituir. (M2)

A infecção pelo HIV e a impossibilidade de amamentar naturalmente seu filho conduzem a mãe com diagnóstico de soropositividade para este vírus a enfrentar processos biológicos, emocionais, psicológicos e sociais os quais despertam nelas sentimentos de medo, tristeza, dor, angústia e culpa ${ }^{3}$. $\mathrm{O}$ ideal seria que todas as gestantes infectadas recebessem, durante o pré-natal, não só as instruções sobre o risco de transmissão do vírus para o bebê como os procedimentos que deverão ter para evitar a amamentação natural da criança, como enfaixamento dos seios, fármacos para secagem do leite e a indicação do leite artificial para substituir o leite materno. Tais informações no pré-natal evitariam que o momento do parto seja traumático para essas gestantes ${ }^{9}$.

A forma como a equipe de saúde acolhe e as orientações transmitidas influenciam a maneira como as puérperas aderem aos cuidados e lidam com as implicações do reverso da amamentação. Percebe-se que, apesar do forte impacto desse processo, o vínculo afetivo com os filhos mantém-se presente e o fato de não poder amamentar não afeta o papel de mãe e nem prejudica a relação materno-filial.

\section{Enfrentando as implicações decorrentes do reverso da amamentação}

A indicação médica para a supressão da lactação foi realizada para a maioria das mães. No entanto, uma delas não teve essa indicação e outra não produziu leite. Entre as indicações, o enfaixamento das mamas foi o mais indicado, mas houve indicação de remédios orais e injetáveis e até o uso de mais de uma técnica simultaneamente. $\mathrm{O}$ momento dessa indicação ocorreu mais intensamente no pré-natal, mas foi realizado também na maternidade, no pós-parto. 
Constatou-se que o sentimento predominante das mães, ao passarem pelo procedimento de secagem do seu leite, foi de tristeza, seguido por um conformismo relacionado à consciência do risco da transmissão vertical.

Enfaixaram meu peito foi muito doloroso, meu peito empedrou eu tive febre e quando eu cheguei em casa eu tomei dois comprimidos e, em uma semana, meu leite secou. (M10)

É psicológico, doer não dói, mas é como se estivesse tirando um pedaço de mim, nos privando daquilo. (M12)

É importante informar, ainda no pré-natal, às mães infectadas pelo HIV, os riscos de transmissão pela amamentação, pois possibilita à gestante um tempo para assimilar o fato de não amamentar o bebê, decidir se quer ou não utilizar alguma técnica de secagem do leite, assim como escolher qual tipo de alimento será fornecido ao filho no lugar do leite materno ${ }^{13}$.

Percebe-se, pelos depoimentos, que o leite artificial industrializado foi o principal alimento empregado na substituição do leite materno, em função da distribuição gratuita por parte do governo, o que é visto pelas participantes como uma importante ajuda. Outros substitutos do leite materno mencionados foram o leite de vaca e o de soja.

Ainda assim, para as mães é constrangedor e estressante o momento de oferecer a mamadeira a seus filhos diante de pessoas desinformadas de sua soropositividade, pois é nesse momento que ocorrem as maiores cobranças quanto à amamentação natural. Isso propicia até que essas mães omitam o fato de não estarem amamentando ou mintam sobre os seus reais motivos.

Eu falava que meu leite secou. Porque eles faziam muita pergunta e mesmo assim ainda perguntavam por que secou. Mas eu sempre estava com a resposta ali, tranquila para passar para eles. (M18)

Eu recebi a orientação da enfermeira para falar que eu estava tomando um medicamento forte e por isso não podia amamentar meu filho. (M20)

O preconceito social em torno do HIV associa-se à própria origem da epidemia a qual se supunha atingir somente os chamados grupos de risco (homossexuais masculinos, usuários de drogas injetáveis, receptores de transfusão de produtos sanguíneos). Tal suposição criou no subconsciente das pessoas a concepção de que a mulher que não tivesse um comportamento sexual promíscuo, não pegaria o vírus ${ }^{3}$.

\section{CONCLUSÃO}

Os resultados do estudo revelam o descobrir-se mãe e portadora do HIV, evidenciando o impacto do diagnóstico e os temores pelo preconceito da sociedade, reforçando o medo da transmissão vertical ao seu concepto. Ser mãe e portadora do HIV traduz sentimentos que derivam da indiferença ao temor em revelar seu diagnóstico à família e pessoas próximas.
O receio de ter seus nomes associados ao HIV é tão expressivo que, mesmo esclarecidas, algumas mães sentiram-se impedidas de registrar suas histórias, sendo esta uma das limitações deste estudo. Embora não aceitassem participar, ficou evidente a necessidade dessas mulheres em desabafar suas histórias e conflitos repletos de preconceito social.

Amamentar é compreendido como um sonho que não pode fazer parte da realidade. Para aquelas que já amamentaram em gestações anteriores, a doença representa uma privação em assumir seu papel de mãe. Já para quem não passou por essa experiência, torna-se indiferente - o fundamental é não transmitir a doença aos seus filhos.

Verificam-se ainda as implicações e os mecanismos de enfrentamento presentes no reverso da amamentação, que geram a necessidade de uma assistência de enfermagem qualificada. Para tanto, percebe-se a importância da realização de um pré-natal de qualidade, uma vez que a maioria das depoentes descobriu ter contraído o HIV durante esse período.

À guisa de conclusão, o enfermeiro é essencial na efetivação de um cuidado humanizado às mães com diagnóstico de soropositividade para o HIV. Além da importância das orientações fornecidas a elas, o enfermeiro proporciona subsídios para o enfrentamento das principais dificuldades vivenciadas por essas mães. Para isso, é imprescindível uma aproximação da realidade dessas mulheres, ouvindo-as e permitindo que elas expressem sentimentos e dúvidas. Assim, torna-se possível esclarecer e perceber possíveis riscos à saúde da mãe e do filho, além de criar medidas que tornem mais branda a vivência dessa realidade.

\section{REFERÊNCIAS}

1.Pan American Health Organization, World Health Organization, Fundo das Nações Unidas para a Infância (UNICEF), Unaids (Joint united nations programme on HIV/ AIDS). 2014 Update: Elimination of mother-tochild transmission of HIV and syphilis in the Americas. Washington (DC): PAHO; 2014.

2.Kleinübing RE, Lipinski JM, Pereira FW, Fonseca AD, Chagas MCS, Ilha S. Puérperas soropositivas para o HIV: como estão vivenciando a não amamentação. Rev enferm UFPE on line. 2014; 8: 107-13.

3.Batista CB, Silva LR. Sentimentos de mulheres soropositivas para HIV diante da impossibilidade de amamentar. Esc Anna Nery. 2007; 11: 268-75.

4.Porto TSAR, Silva CM, Vargens OM. Cuidando de mulheres com HIV/AIDS: uma análise interacionista na perspectiva de mulheres profissionais de saúde. Rev Gaúcha Enferm. 2014; 35: 40-6.

5.Schaurich D, Coelho DF, Motta MGC. A cronicidade no processo saúde-doença: repensando a epidemia da AIDS após os anti-retrovirais . Rev enferm UERJ. 2006; 14: 455-62. 
6.UNAIDS. Programa Conjunto das Nações Unidas sobre HIV/AIDS. 2014. The Gap Report. Beginning of the end of the AIDS epidemic. Genebra (Swi): UNAIDS; 2014. 7.Leal AF, Roese, A, Sousa, AS. Medidas de prevenção da transmissão vertical do HIV empregadas por mães de crianças o positivas. Investigación y Educación en Enfermería. 2012; 30:44-54.

8.Soropositivo.org [Internet] 2015. A transmissão vertical. [citado em julho 2014] Disponível em: http://soropositivo. net.br/hiv-aids-hpv-hepatite/a-transmissao-vertical.html. 9.Ministério da Saúde (Br). Protocolo de investigação de transmissão vertical. Brasília (DF): Ministério da Saúde; 2014.

10.Fonte VRF, Spindola T, Martins ERC, Francisco MTR, Clos AC, Pinto RC. Conhecimento de gestantes de um hospital universitário relacionado à prevenção de DST/ AIDS. Rev enferm UERJ. 2012; 20: 493-9.

11.Schaurich D, Medeiros HMF, Motta MGC. Vulnerabilidades no viver de crianças com AIDS. Rev enferm UERJ. 2007; 15: 284-90.

12.Bardin L. Análise de conteúdo. Lisboa (Pt): Edições $70 ; 2008$.
13.Ministério da Saúde (Br). Secretaria de vigilância em Saúde. Departamento de DST/AIDS e hepatites virais. Recomendações para profilaxia da transmissão vertical do HIV e terapia antirretroviral em gestantes. Brasília (DF): CNDST/AIDS; 2010.

14.Moreno CCGS, Filipe EV, Rea MF. Mães HIV positivo e a não-amamentação. Rev Bras Saude Mater Infant. 2006; 6: 199-208.

15.Araújo MAL, Silveira CB, Silveira CB, Melo SP. Vivências de gestante e puérperas com o diagnostico do HIV. Rev Bras Enferm. 2008; 61: 589-94.

16.Barros CS, Queiroz PP, Javorski M, Vasconcelos MGL, Vasconcelos EMR, Pontes CM. Significados da vivência do amamentar entre as enfermeiras da área maternoinfantil. Rev enferm UERJ. 2012; 20: 802-7.

17.Gomes GC, Pintanel AC, Strasburg A, Xavier DM. Face singular do cuidado familiar à criança portadora do vírus HIV/AIDS. Acta Paul Enferm. 2012; 25: 749-54.

18.Freitas JG; Barroso LMM; Galvão MTG. Capacidade de mães para cuidar de crianças expostas ao HIV. Rev Latino-Am Enfermagem. 2013; 21: [09 telas]. 